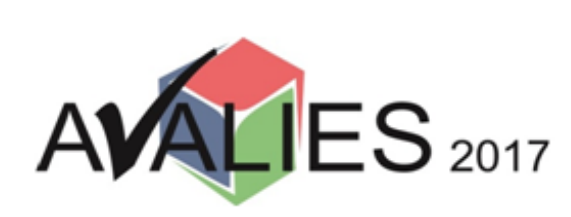

$3^{\circ}$ Simpósio Avaliação da Educação Superior

05 e 06 de setembro de 2017

Florianópolis - SC-Brasil

ISBN: 978-85-68618-04-2

\title{
AVALIAÇÃO DA FORÇA DA MARCA EM UMA INSTITUIÇÃO DE ENSINO SUPERIOR
}

\author{
LUIZ RODRIGO CUNHA MOURA \\ Centro Universitário UNA / Centro Universitário Belo Horizonte - UniBH \\ luizrcmoura@gmail.com \\ PAULO ROBERTO FERREIRA \\ Centro Universitário UNA \\ paulo.vivid@gmail.com \\ ALESSANDRA DUARTE DE OLIVEIRA \\ Centro Universitário UNA \\ alessandra.duarte@gmail.com \\ PAULO HENRIQUE DOS SANTOS \\ Centro Federal de Educação Tecnológica de Minas Gerais - CEFET/MG \\ ph.cefet@gmail.com
}

\section{RESUMO}

O objetivo desse trabalho foi o de mensurar o brand equity da marca de uma IES por meio dos seis blocos - proeminência, imagem, desempenho, sentimento, julgamento e ressonância - da Pirâmide de Ressonância da Marca, além de também mensurar a confiança na marca e calcular as correlações entre os próprios blocos de ressonância de marca e também a confiança. Foram aplicados 491 questionários para os alunos que estudavam em quatro campi da IES. Os resultados indicam que a IES possui os blocos mais fortes da Pirâmide de Ressonância de Marca em termos da proeminência, imagem e julgamento da marca. Além disso, conforme descrito na teoria, o brand equity se inicia na proeminência de marca e termina na ressonância de marca. Todavia, para que a ressonância de marca possa ocorrer, os blocos anteriores devem ser alcançados a partir da percepção dos consumidores. Também foram calculadas as correlações entre os blocos e se alcançou a validade nomológica. No caso da confiança, ela possui uma grande correlação conforme também descrito na teoria. A IES possui uma boa imagem e é facilmente reconhecida e lembrada pelos seus alunos, mas precisa melhorar bastante principalmente os aspectos relacionados à ressonância de marca e à confiança na marca.

Palavras chave: Brand Equity. Ressonância de marca. Gestão de Marcas. 


\section{INTRODUÇÃO}

A marca excedeu a sua simples função de identificação do produto ou serviço. Atualmente, ela se traduz como patrimônio da empresa, além do fato de ser uma propriedade exclusiva e vitalícia da organização, de acordo com a legislação e especialmente, por possibilitar a diferenciação e vantagem competitiva pela distinção que provoca entre produtos concorrentes (KELLER, 2001).

Atualmente, estudos indicam que o brand equity é um dos principais objetivos das empresas líderes de mercado, bem como um dos principais assuntos estudados relacionados ao marketing. A sua importância não está somente presente nas empresas que trabalham com bens tangíveis, mas também para aquelas que trabalham com serviços, ou seja, trabalham com produtos intangíveis (BASTOS; MOURA; CHRISTINO, 2014; AZIZ; YASIN, 2010).

A estruturação teórica adotada neste estudo é o valor da marca baseado no cliente (CBBE - Customer Based Brand Equity), que é composto por seis blocos fundamentais, a saber: proeminência, performance, imagem, julgamento, sentimento e ressonância (KELLER, 2001). Mais especificamente, a pesquisa investiga a aplicação do modelo CBBE de ressonância da marca e procura mensurar cada um desses blocos em relação à marca de uma IES (Instituição de Ensino Superior) brasileira.

Por conseguinte, o objetivo desse estudo é mensurar a ressonância da marca de uma IES a partir da percepção dos seus alunos por meio da aplicação de uma escala para medir não somente a ressonância de marca, mas também os seus seis blocos que compõem esse construto proposto por Keller (2001), além da confiança na marca da IES. Além disso, esse estudo busca analisar o nível de correlação entre os blocos da ressonância de marca entre si, além da correlação desses blocos com a confiança na marca.

Em termos teóricos, esse trabalho contribui para o maior conhecimento acerca da aplicação do Modelo de Ressonância de Marca no Brasil, haja vista que pesquisas ocorridas em bases de dados como o banco de teses da CAPES (Comissão de Aperfeiçoamento de Pessoal do Nível Superior), banco de revistas do Scielo (Scientific Electronic Library Online) e google scholar não encontraram pesquisas sobre a ressonância de marca no Brasil e em termos internacionais, nenhum trabalho na área de educação ou de IES. O foco das pesquisas internacionais está voltado para o setor bancário (VERMA, 2012; GAUTAM; KUMAR, 2012; AZIZ; YASIN, 2010).

Além dos blocos que compõem a Pirâmide de Ressonância de marca, outros dois construtos também exercem papel fundamental na ressonância de marca e no relacionamento entre as marcas e os seus consumidores. Além disso, esses dois construtos podem ser considerados um resumo de vários blocos da Pirâmide de Ressonância de Marca e por isso também devem fazer parte dos estudos sobre o relacionamento da marca e os seus consumidores (RAUT; BRITO, 2014).

Em muitos estudos, a confiança na marca tem sido avaliada como uma variável moderadora em termos das suas consequências ou como antecedente em termos do relacionamento da marca. Todavia, ela deve ser considerada não somente como uma moderadora, mas também como um dos pilares em termos do relacionamento das marcas com os seus consumidores (RAUT, 2015), além de existir uma forte relação entre a lealdade à marca e a confiança na marca (CHAUDHURI; HOLBROOK, 2001). A elaboração de instrumentos para medir de forma adequada a confiança na marca ainda é considerada para muitos um grande desafio a ser transposto (RAUT, 2015). 
Em termos gerenciais, destaca-se que a escala de brand equity baseada no consumidor é funcional para processar informações e construir confiança na decisão de compra e para aumentar a eficiência e eficácia de programas de marketing, preço, lucros e extensões de marca, e alavancagem comercial (YOO; DONTHU, 2001).

Sob o ponto de vista das organizações é primordial que o consumidor tenha uma forte identificação com a sua marca. Uma vez estabelecida essa identificação pode ser gerenciada e trabalhada uma perspectiva de relacionamento com seus desdobramentos de preferência e fidelização (FARHANA; ISLAM, 2012).

Um esforço de construção de marca cuidadosamente construído baseado no modelo CBBE pode ajudar as empresas a alcançar a ressonância da marca. As empresas que conseguem alcançar a ressonância e afinidade com seus clientes devem colher uma série de benefícios valiosos, tais como preços premium (mais elevados) e programas de marketing eficazes. Usando o modelo CBBE, os profissionais de marketing podem avaliar melhor como os esforços de construção de marca estão progredindo e podem criar iniciativas bem sucedidas de pesquisa de marketing (KELLER, 2001).

\section{REFERENCIAL TEÓRICO}

O referencial será composto por três partes principais. A primeira diz respeito aos conceitos relacionados ao brand equity. Em seguida é apresentado o Modelo de Ressonância de Marca (KELLER, 2001), bem como os seus blocos, as suas definições e implicações teóricas e gerenciais. Por fim, são descritos os conceitos, os dois componentes e a importância da confiança da marca para as organizações.

\subsection{BRAND EQUITY}

O conceito de Brand Equity surgiu na década de 1980 e implicou na criação de vários métodos e modelos que objetivam mensurar o capital das marcas. De forma simples, o valor da marca é entendido como o valor agregado ao produto ou ao serviço (LOURO, 2000). Apesar do Modelo de Ressonância de Marca ter sido criado no início desse século, ele ainda é relevante tanto em termos acadêmicos, quanto em termos gerenciais. Apesar de ter sido criado bem antes das mídias sociais existentes atualmente, o Modelo de Ressonância de Marca possui blocos capazes de absorver as novas relações, sentimentos e ações pelas quais os consumidores interagem por meio das mídias sociais, abrangendo desde a lealdade comportamental, passando pelo senso de comunidade até chegar ao engajamento ativo pelos consumidores em relação à marca (KELLER, 2016).

A equidade (ou valor) da marca sob a ótica do consumidor é, um conjunto de recursos e deficiências, inerentes a uma marca, que agregam ou subtraem valor a um produto ou serviço (AAKER, 1998). O principal influenciador das respostas por parte do consumidor é o conhecimento que esse tem da marca. O conhecimento é formado pela consciência ou

lembrança da marca e pela imagem de marca. A marca tem valor aos olhos do consumidor quando este é familiar à marca e guarda na memória algumas associações favoráveis, fortes e únicas (KELLER, 2001).

O conceito do brand equity é multidimensional (GAUTAM; KUMAR, 2012), envolvendo vários construtos e concomitantemente diversos modelos de equidade de marca têm sido propostos por pesquisadores ao longo de um período de tempo (KELLER, 2001; 
TAVARES, 2008), os quais fornecem perspectivas distintas sobre o brand equity (KOTLER; KELLER, 2012).

São quatro os modelos principias para avaliar o brand equity: Brand Asset Valuator, modelo de Aaker, Brandz e a Ressonância de Marca (KOTLER; KELLER, 2012). Em síntese os modelos trabalham a partir de variáveis que incluem, dentre outras: diferenciação, estima, conhecimento, e desempenho, tais como o Modelo Aaker de Equidade de Marca, o Modelo de Equidade de Marca Baseado no Cliente (CBBE) e a Ressonância de Marca de Keller, o Modelo BrandZ de força da marca criado pelas consultorias de pesquisa de marketing do Consultor Millward Brown e WPP, e o Avaliador de Ativo de Marca (BrandAsset ${ }^{\circledR}$ Valuator) pela Agência de publicidade Young e Rubicam (GAUTAM; KUMAR, 2012).O modelo do Avaliador de Ativo de Marca (BAV) oferece medidas comparativas de milhares de marcas, em centenas de categorias com base em pesquisa com aproximadamente 800 mil consumidores e 51 países (KOTLER; KELLER, 2012).

A premissa do modelo de brand equiy da marca baseada no consumidor é que o poder de uma marca reside no que os clientes têm aprendido, sentido, visto e ouvido falar sobre a marca ao longo do tempo. O poder de uma marca reside na mente dos clientes. $\mathrm{O}$ desafio dos profissionais de marketing na construção de uma marca forte é o de garantir que os clientes têm as experiências desejadas com produtos e serviços de tal forma que seus pensamentos, sentimentos, imagens, percepções e atitudes tornem-se ligados à marca (KELLER, 2001).

O relacionamento do consumidor com a marca é baseado em diversos contatos do mesmo com a marca e o seu valor pode ser expresso a partir da percepção de quão valioso é para ele um determinado produto, serviço ou solução, quando comparado com outro. Se o valor da marca aumentar ao longo do tempo espera-se que o cliente continue fiel (GRONROOS, 2003).

\subsection{MODELO DE RESSONÂNCIA DE MARCA}

O modelo do valor da marca baseado no consumidor, também conhecido como "Customer Based Brand Equity" - (CBBE), elaborado por Keller (1993) estabelece uma perspectiva própria, do significado do valor da marca e de como o mesmo deve ser construído, medido e gerido. Para Keller (2001) a marca é algo que reside na mente dos consumidores e se eles a reconhecem e guardam qualquer tipo de informação sobre ela, então a as decisões de consumo serão facilitadas e menos exaustivas.

De acordo com Keller (2001). Tsai, Lin e Li (2014) e Ahrens (2016) para se construir uma marca forte, os quatro passos seguintes devem ser seguidos:

- Estabelecer uma identidade de marca e posicionamento da marca na mente dos consumidores.

- Unir estrategicamente a marca com ativos tangíveis e intangíveis e criar um significado de marca na mente dos consumidores.

- Desencadear respostas positivas da marca dos consumidores.

- Com base em respostas positivas, criar uma relação ativa e leal entre os clientes e a marca.

Assim, o modelo de ressonância da marca apresentado pela Keller (2001) sugere que a construção da marca é uma série de passos a partir da notoriedade da marca e passando pelo desempenho da marca, pelos julgamentos da marca e pelos sentimentos da marca. O resultado é a ressonância da marca. Assim, todas as etapas estão inter-relacionadas (SANDHE, 2016). 
Construir uma marca forte, de acordo com o modelo CBBE, pode ser pensado como uma série de etapas, onde cada passo à frente implica em ter que alcançar êxito no passo anterior. Os passos nessa "escada de branding" seguem uma ordem, da identidade ao significado, das respostas aos relacionamentos com a marca. $\mathrm{O}$ significado não pode ser estabelecido sem primeiro criar identidade. As respostas não podem ocorrer a menos que as empresas desenvolvam o significado correto da marca, e um relacionamento não pode ser forjado sem obter as respostas apropriadas dos clientes (KELLER, 2001).

O modelo de ressonância da marca é formado por seis blocos: a saliência da marca, o desempenho da marca, a imagem da marca, o julgamento da marca, os sentimentos de marca e a ressonância da marca, os quais definem a força da marca (KELLER, 2016; 2001; AHRENS, 2016; SANDHE, 2016; FARHANA; ISLAM, 2012).

A Pirâmide de Ressonância da Marca constitui um meio de rastrear a relação entre a comunicação de marketing e a lealdade ativa dos consumidores e como esse relacionamento está sendo afetado pelo valor da marca (GAUTAM; KUMAR. 2012).

A ressonância da marca reflete uma relação completamente harmoniosa entre os clientes e a marca. Uma marca com a identidade correta e significado pode resultar em um cliente acreditando que a marca é relevante para ele. As marcas mais fortes serão aquelas para as quais esses consumidores ficam tão ligados que, na verdade, se tornam defensores da marca e buscam ativamente meios de interagir com a marca e compartilhar suas experiências com os outros (RAUT, 2015). A vantagem da ressonância da marca associada ao brand equity está justamente na sua dualidade conceitual emocional e racional, pois o consumidor percebe o valor da marca nas duas dimensões simultaneamente. É importante mencionar que este modelo inclui atributos valor da marca, bem como as suas ligações (KELLER, 1993).

A figura 1 apresenta as quatro etapas bem como os seis blocos que a estruturam e suas sub-dimensões, sendo que a primeira etapa compreende a proeminência de marca e a quarta e última etapa se refere à ressonância de marca.

Figura 1 - Pirâmide das quatro etapas do processo de construção do brand equity, os seis blocos e as suas sub-dimensões

\begin{tabular}{|c|c|c|c|}
\hline ETAPAS & OS SEIS BLOCOS & \multicolumn{2}{|c|}{ SUBDIMENSÕES DOS BLOCOS } \\
\hline $\begin{array}{l}4 \\
\text { Relacionamentos } \\
: \\
\text { Que } \\
\text { relacionamento } \\
\text { quero com você? }\end{array}$ & Resso & $\begin{array}{l}\text { Ressonância: } \\
\text { Fidelidade } \\
\text { Adesão } \\
\text { Engajamento }\end{array}$ & \\
\hline $\begin{array}{l}3 \\
\text { Respostas: } \\
\text { O que penso de } \\
\text { você? }\end{array}$ & Julgamentos Sensaçōes & $\begin{array}{l}\text { Julgamentos: } \\
\text { Qualidade } \\
\text { Credibilidade } \\
\text { Consideração } \\
\text { Superioridade }\end{array}$ & $\begin{array}{l}\text { Sensações: } \\
\text { Ternura, } \\
\text { Diversão } \\
\text { Entusiasmo, } \\
\text { Segurança } \\
\text { Aceitação } \\
\text { social } \\
\text { Autoestima }\end{array}$ \\
\hline
\end{tabular}




\begin{tabular}{|c|c|c|c|c|}
\hline $\begin{array}{l}2 \\
\text { Significado: } \\
\text { O que você é? }\end{array}$ & Desempenho & Imagem & $\begin{array}{l}\text { Desempenho: } \\
\text { Características primárias e } \\
\text { aspectos secundários; } \\
\text { Confiabilidade, } \\
\text { durabilidade } \\
\text { e disponibilidade de } \\
\text { serviços / assistência do } \\
\text { produto; } \\
\text { Efetividade, eficiência, } \\
\text { e empatia do serviço; e } \\
\text { Estilo e design. }\end{array}$ & $\begin{array}{l}\text { Imagem: } \\
\text { Perfis dos } \\
\text { usuários; } \\
\text { Situações de } \\
\text { compra } \\
\text { e utilização; } \\
\text { Personalidade } \\
\text { e valores; } \\
\text { História, } \\
\text { legado, } \\
\text { e experiências. }\end{array}$ \\
\hline $\begin{array}{l}1 \\
\text { Identificação: } \\
\text { Quem é você? }\end{array}$ & & & $\begin{array}{l}\text { Proeminência: } \\
\text { Identificação de categoria; } \\
\text { Necessidades satisfeitas }\end{array}$ & \\
\hline
\end{tabular}

Fonte: Adaptado de Keller (2016; 2001).

O primeiro bloco da pirâmide é a proeminência da marca, a qual está ligada à capacidade dos consumidores em reconhecerem a se lembrarem da marca. É a força de lembrança da marca em diversas situações pelas quais o consumidor percorre em seu processo de compra. A comunicação de marketing exerce papel fundamental na criação da proeminência (KELLER, 2001; RAUT, 2015; ADRIAN, 2014; TRI, 2014).

O desempenho é outro bloco que forma a Pirâmide de Ressonância da Marca e está relacionado com a capacidade da marca em cumprir as suas promessas. O desempenho está fortemente relacionado com os atributos técnicos do produto ou serviço, bem como com o desempenho funcional deles (KELLER, 2001; BAIRD, 2015; RAUT, 2015).

A imagem faz parte do caminho emocional da Pirâmide de Ressonância de Marca e ao contrário do desempenho, está relacionada com os aspectos intangíveis da marca, procurando atender às necessidades psicológicas e/ou sociais dos consumidores (KELLER, 2001; RAUT, 2015; TRI, 2014; CHOUDHURY; KAKATI, 2014).

No caminho racional da marca, o julgamento é a continuação do desempenho da marca. O julgamento pode ser definido como as avaliações, crenças e atitudes do consumidor e em relação à marca. Ele é formado basicamente pela qualidade, credibilidade, consideração e superioridade da marca (KELLER, 2001; TRI, 2014; MÁRKUS; FALLMYR, 2014).

Os sentimentos são a continuação do caminho emocional da Pirâmide de Marca, sendo fortemente afetado pela imagem. Os sentimentos são as sensações ou reações a marca gera nos consumidores em seus diversos momentos de compra ou consumo do produto. Eles podem ser positivos ou negativos e de alta ou baixa intensidade (KELLER, 2001; SANDHE, 2016; RAUT, 2015; ADRIAN, 2014).

A ressonância é a intensidade do vínculo psicológico dos clientes com a marca e o nível de atividade que ela gera. Ela refere-se à natureza do relacionamento entre os clientes e a marca e se eles se consideram alinhados com a mesma. A ressonância da marca é caracterizada pela profundidade da conexão psicológica que os clientes têm com a marca, e pelo nível de atividade gerada por esta fidelidade, a qual pode ser comportamental por exemplo. No caso das conexões psicológicas com a marca, os consumidores podem agir como defensores da marca, propagando comunicações positivas em relação à marca (KELLER, 2001; SANDHE, 2016; RAUT, 2015; CHOUDHURY; KAKATI, 2014). 


\subsection{CONFIANÇA NA MARCA}

A confiança na marca pode ser descrita como um reflexo de crenças que o consumidor possui em relação à marca, envolvendo a credibilidade, a integridade e a benevolência que um consumidor atribui a marca (GURVIEZ; KORCHIA, 2003), como uma atitude que possui a intenção de aceitar o relacionamento com a empresa baseada nas suas expectativas positivas em relação às experiências desse relacionamento (KAVEH; MOSAVI; GHAEDI, 2012).

O nível de confiança foi conceituado como o nível de interação percebido pelos consumidores entre a empresa que fornece a informação e os consumidores que recebem essa informação. Qualquer relacionamento pessoal ou interpessoal quer entre uma pessoa ou uma empresa, é construído na confiança (KAVEH; MOSAVI; GHAEDI, 2012)

A confiabilidade é formada a partir de duas dimensões (KAVEH; MOSAVI; GHAEDI, 2012; BALLESTER, 2004). A primeira delas é relativa ao desempenho da marca, ou seja, a capacidade da marca em cumprir as suas promessas e dependente dos atributos do produto ou serviço (CRUZ, 2013; TERRES et al., 2010; ROSEMBERGER III, 2009; CHAUDHURI; HOLBROOK, 2001), sendo fundamental para a criação e manutenção da confiança ao longo do tempo (CRUZ, 2013; KOETZ et al., 2009; BALLESTER, 2004).

A segunda dimensão e a intenção da marca, representada pela a integridade e o altruísmo da empresa por trás da marca, que refletem a percepção dos consumidores de que a empresa por trás da marca realmente se preocupa com os seus clientes e que ela está disposta a ser honesta e sincera em suas relações de consumo (TERRES et al., 2010), colocando os interesses dos consumidores à frente dos seus próprios interesses quando houver falhas por parte da empresa na prestação dos serviços ou no desempenho dos produtos, não se aproveitando de situações desfavoráveis para os consumidores, buscando o seu bem-estar (BALLESTER, 2004; BALLESTER; ALEMÁN, 2003).

Isso ajuda a explicar porque clientes satisfeitos podem não confiar na marca. A satisfação é um requisito para a confiança, mas não garante a sua existência (KAVEH; MOSAVI; GHAEDI, 2012) e é construída a partir da experiência com a marca (BALLESTER; ALEMÁN, 2001).

Uma das formas de se criar confiança na marca é a as empresas se preocuparem em resolver rapidamente os problemas dos seus clientes, oferecendo uma experiência diferenciada e mostrando a suas intenções do relacionamento com os seus clientes (TERRES et. al,. 2010). Em relação à importância da confiança, ela tem um importante papel durante o processo de compra por parte do consumidor influenciando o seu comportamento ao longo do tempo (JÄRVENPÄ̈̈; STAPLES, 2000; KAVEH; MOSAVI; GHAEDI, 2012) e também diminuindo a sua percepção de incerteza, percepção de risco e potencializando a sua lealdade e relações duradouras com a empresa (BASTOS; MOURA; CHRISTINO, 2015; CRUZ, 2013; BALLESTER; ALEMÁN, 2001). A confiança na marca é um dos pilares do marketing de relacionamento (KAU; LOH, 2006).

O desenvolvimento de marcas confiáveis pode sinalizar para os consumidores que a qualidade dos produtos e serviços da empresa são altos, novamente reduzindo a incerteza e o risco da aquisição de produtos e serviços, e, influenciando positivamente as transações (BASTOS; MOURA; CHRISTINO, 2015; TERRES et. al., 2010; KOETZ et al., 2009).

\section{METODOLOGIA}


Esta é uma pesquisa descritiva com abordagem quantitativa para a análise de dados. $\mathrm{O}$ objetivo é o de mensurar a ressonância da marca e a confiança que os alunos de uma IES depositam nessa marca.

Para a elaboração do instrumento de coleta de dados foram usados estudos nos quais as escalas para os seis blocos da Pirâmide de Ressonância de Marca já foram pré-definidos, tais como em Raut (2015), Choudhury e Kakati (2014), Farhana e Islam (2012) e Aziz e Yasin (2010). Além disso, para a mensuração da confiança na marca, foi usada a escala usadas nos estudos de Ballester (2004) e Bastos, Moura e Christino (2014).

Em relação à confiança, a escala utilizada foi baseada nos estudos de Ballester (2004) e de Bastos, Moura e Christino (2015).

As âncoras usadas no questionário foram "discordo totalmente" e "concordo totalmente". A escala usada foi do tipo intervalar com onze pontos e com o escalonamento variando entre 0 e 10 pontos. Esse tipo de escalonamento permite registrar com maior nível de detalhe e nível de precisão as variações das opiniões dos respondentes (NUNNALY; BERNSTEIN, 1994; FORNELL et al., 1996).

Há de se considerar que antes de se proceder ao processo de coleta de dados, foi realizado um pré-teste com quarenta alunos dessa IES com o intuito de verificar possíveis problemas e inconsistências com o instrumento de coleta de dados. Os resultados indicaram que o questionário não apresentou nenhum problema e que a versão final foi a mesma versão usada no pré-teste. As queixas dos respondentes foram relacionadas ao conteúdo das escalas, as quais pareceram como uma série de itens para "pegadinhas", questões idênticas, grande número de questões e questionário trabalhoso de responder.

A amostra foi composta por alunos de uma IES situada no sudeste do Brasil. Foram entrevistados alunos de 4 campi dessa IES perfazendo um total de 491 questionários válidos. Os alunos foram escolhidos em termos de conveniência e disponibilidade de participar da pesquisa. Assim, a amostra pode ser considerada como uma amostra por conveniência.

O questionário tinha duas questões idênticas. O objetivo foi testar o nível de atenção e comprometimento dos respondentes em relação ao preenchimento do questonário. Os questionários que apresentaram uma diferença acima de dois pontos para as questões idênticas foram descartados e a amostra final ficou composta por 442 elementos - 49 foram eliminados.

\section{ANÁLISE DE DADOS}

A análise de dados foi dividida em três itens principais. O primeiro deles é a apresentação das características da amostra em termos de gênero e renda média mensal. Em seguida são apresentados os valores médios para todos os itens do questionário, bem como para os construtos que formam a Pirâmide de Ressonância de Marca, além do construto confiança. Por fim, é apresentada a correlação entre todos os construtos - os seis blocos da Pirâmide de Ressonância de Marca -, bem como as suas relações com o construto confiança.

\subsection{CARACTERIZAÇÃO DA AMOSTRA}

Como a amostra foi formada por alunos de uma IES, variáveis como idade e nível de escolaridade não foram coletadas em relação à amostra, sobre a qual somente dois parâmetros foram coletados. O primeiro deles diz respeito ao gênero (sexo) cerca de 61,3\% (271 alunas 
em números absolutos) dos respondentes era do sexo feminino, 37,3\% eram do sexo masculino e $1,4 \%$ dos respondentes deixaram essa questão sem resposta.

O segundo parâmetro observado em relação à amostra foi a renda mensal familiar. Nesse caso, 40,3\% dos respondentes apresentaram essa renda estava entre R $\$ 1761,00$ e $R$ \$ 4.400,00, o que equivalia na época da aplicação do questionário a um valor entre dois e cinco salários mínimos. O segundo maior grupo - com $26,7 \%$ do total de respondentes - foi formado por alunos que apresentaram uma renda familiar mensal de até $\mathrm{R} \$ 1761,00$, o que equivale a menos de dois salários mínimos na época da coleta de dados.

Isso significa que aproximadamente $67 \%$ ou mais de dois terços dos respondentes pertencem a famílias que recebem até cinco salários mínimos.

\subsection{ANÁLISE DESCRITIVA}

O próximo passo foi a análise das médias para cada item dos seis blocos da Pirâmide de Ressonância da Marca, bem como a média dos itens que formam a confiança na marca.

A análise apresenta também a média em relação a cada um dos seis blocos de forma isolada como também a média geral para o construto confiança. No questionário aplicado aos alunos constava o nome da IES. Nesse artigo, optou-se por apresentar o termo "IES" para substituir o nome da marca da universidade. Os resultados estão na Tabela 1 a seguir.

Tabela 1: Média dos itens de ressonância de marca, dos seus blocos e da confiança na marca

\begin{tabular}{|c|c|c|c|}
\hline $\begin{array}{c}\text { Pilar da } \\
\text { Ressonância } \\
\text { da Marca } \\
\end{array}$ & Questões & $\begin{array}{c}\text { Média } \\
\text { dos } \\
\text { itens }\end{array}$ & $\begin{array}{c}\text { Média } \\
\text { do } \\
\text { Pilar }\end{array}$ \\
\hline \multirow{3}{*}{ Proeminência } & $\begin{array}{c}\text { Eu posso reconhecer a marca da IES em relação às outras marcas de } \\
\text { Faculdades e Universidades }\end{array}$ & 8,20 & \multirow{3}{*}{8,32} \\
\hline & $\begin{array}{l}\text { Eu posso lembrar facilmente da marca ou do símbolo ou do logotipo } \\
\text { da IES }\end{array}$ & 8,38 & \\
\hline & A marca da IES é bem fácil de ser reconhecida & 8,37 & \\
\hline \multirow{4}{*}{ Desempenho } & $\begin{array}{l}\text { Em comparação com outras Faculdades e Universidades, a IES oferece } \\
\text { o melhor ensino. }\end{array}$ & 6,78 & \multirow{4}{*}{6,96} \\
\hline & A IES atende às minhas expectativas & 6,94 & \\
\hline & O ensino da IES é muito bom. & 7,18 & \\
\hline & A IES satisfaz bem as minhas necessidades básicas como aluno. & 6,96 & \\
\hline \multirow{3}{*}{ Imagem } & A aparência do campus da IES é atrativa & 7,23 & \multirow{3}{*}{7,47} \\
\hline & A IES tem uma boa imagem & 7,79 & \\
\hline & As pessoas têm uma imagem positiva da IES & 7,40 & \\
\hline \multirow{4}{*}{ Julgamento } & A minha opinião em geral sobre a IES é boa & 7,48 & \multirow{4}{*}{7,23} \\
\hline & Eu estou satisfeito em ser aluno da IES & 7,43 & \\
\hline & $\begin{array}{c}\text { A IES é superior em comparação com outras Faculdades e } \\
\text { Universidades }\end{array}$ & 6,70 & \\
\hline & A qualidade do ensino da IES é boa. & 7,31 & \\
\hline \multirow{3}{*}{ Sentimentos } & Eu me sinto bem quando eu estudo na IES & 7,36 & \multirow{3}{*}{7,03} \\
\hline & A IES me faz feliz & 6,84 & \\
\hline & Estudar na IES me dá prazer & 6,88 & \\
\hline Ressonância / & $\begin{array}{c}\text { Mesmo que tenham Faculdades e Universidades mais baratas, eu } \\
\text { prefiro estudar na IES. }\end{array}$ & 6,98 & 6,39 \\
\hline
\end{tabular}


Eu sou fiel a IES, quando precisar estudar em Faculdades e

Em relação às Faculdades e Universidades a IES é a minha primeira opção

Se eu tenho condições financeiras, eu prefiro estudar na IES.

Eu sinto confiança na marca da IES

A marca da IES é uma garantia de satisfação interesses

Confiança

A marca da IES é honesta e sincera quando se refere aos meus

Eu poderia contar com a IES para resolver os meus problemas relacionados ao ensino

A IES faria qualquer esforço para me satisfazer como seu aluno

Fonte: Dados da pesquisa.

Os resultados das médias de cada um dos construtos, bem como o seus componentes em termos separados são analisados a seguir.

Em relação à proeminência, esse foi o bloco da Pirâmide de Ressonância da Marca que apresentou o maior valor, com uma média de 8,32 pontos. $\mathrm{O}$ item com a pior avaliação foi "Eu posso reconhecer a marca da IES em relação às outras marcas de Faculdades e Universidades". Todavia, os itens referentes a identificar ou a reconhecer a marca da própria IES obtiveram resultados bastante positivos.

No caso do desempenho, o resultado obtido indica um resultado próximo à avaliação de sete pontos. O item que apresentou a melhor nota foi o "ensino da IES é muito bom" com 7,18 pontos. Todavia, a pior avaliação em termos do desempenho foi o item "Em comparação com outras Faculdades e Universidades, a IES oferece o melhor ensino". Isso indica que os alunos acreditam que o ensino que recebem é de boa qualidade, mas que as outras IES concorrentes oferecem um ensino ainda melhor do que a IES estudada. Isso não deixa de ser um resultado um pouco surpreendente, haja vista que a IES estudada é considerada a melhor IES pública do estado na qual se encontra - de acordo com as notas obtidas pelo ENADE (Exame Nacional de Desempenho de Estudantes) há quatro anos seguidos.

O próximo item a ser avaliado é a imagem, a qual apresentou a segunda melhor avaliação entre todos os blocos da Pirâmide de Ressonância de Marca e também em comparação com a confiança na marca. Os resultados indicam que a imagem que as pessoas têm da IES e que a imagem que a IES passa para a sociedade é muito boa. O que pode ser melhorado nesse aspecto é a aparência dos campi da IES.

Em relação ao julgamento, os resultados obtidos indicam que esse é o bloco com a terceira melhor avaliação da Pirâmide de Ressonância da Marca e também em comparação com a confiança na marca. Os resultados são positivos e o item que "puxou" a média para mais baixo foi "a IES é superior em comparação com outras Faculdades e Universidades", com uma nota de 6,70 pontos. Todos os outros três itens que formam o julgamento apresentaram valores superiores à média do construto de 7,23 pontos. Esse resultado é coerente com o resultado do bloco desempenho no qual a IES estudada teve a pior avaliação quando o seu desempenho em termos do ensino oferecido foi comparado com as outras IES. 
No caso dos sentimentos em relação à marca, os resultados são positivos com uma nota obtida acima de 7 pontos. Os itens "a IES me faz feliz" e "estudar na IES me dá prazer" foram avaliadas abaixo da média do construto. O item "Eu me sinto bem quando eu estudo na IES" obteve uma avaliação de 7,36 pontos. Isso pode ser explicado porque esse item não depende somente da IES, mas também dos relacionamentos com outros alunos e do ambiente no qual o aluno estuda.

A ressonância de marca obteve a pior avaliação considerando os blocos da Pirâmide de Marca com uma avaliação de média de 6,39 pontos. Os resultados indicam que o nível de fidelidade comportamental, bem como a preferência em procurar a IES em termos de estudos futuros estão aquém do nível ideal e que medidas de gestão deverão ser tomadas com o intuito de melhorar a situação atual.

Por fim, foi também avaliada a confiança na marca da IES. Os resultados obtidos indicam que esse foi o pior item avaliado pelos alunos da IES. A média desse construto foi pior do que todos os seis blocos da Pirâmide de Ressonância de Marca com uma avaliação um pouco acima de 6 pontos. Os itens "a IES nunca me decepciona", "a IES me compensaria de alguma forma por qualquer problema com o seu serviço (ensino)" e "a IES faria qualquer esforço para me satisfazer como seu aluno", apresentaram resultados ruins, principalmente o primeiro item. Esse é um item muito importante em termos de marca. No referencial teórico já foram descritas as vantagens e a importância de uma forte confiança na marca por parte dos consumidores e essa baixa avaliação pode ser considerada um ponto fraco da IES considerando os fatores estratégicos pelos quais ela tem controle e gestão.

\subsection{CORRELAÇÃO ENTRE A CONFIANÇA E OS BLOCOS DO MODELO DE RESSONÂNCIA DE MARCA}

O próximo tópico a ser analisado foi a correlação entre os blocos da Pirâmide de Ressonância da Marca, bem como o construto confiança.

A Pirâmide de Ressonância de Marca é composta por seis blocos, iniciando-se na proeminência da marca e terminando com a ressonância da marca. Além disso, ela formada pelo caminho racional passando pelo desempenho e julgamento e pelo caminho emocional, passando pea imagem e sentimentos.

Como os dados são paramétricos, optou-se por realizar uma correlação de Pearson (HAIR et al., 2009; MALHOTRA, 2011).

As correlações entre os blocos e a confiança são apresentadas na Tabela 2 a seguir.

Tabela 2: Correlação entre a confiança os blocos da Pirâmide de Ressonância de Marca

\begin{tabular}{|c|c|c|c|c|c|c|c|}
\hline Blocos & Proeminência & Desempenho & Imagem & Julgamento & Sentimento & Ressonância & Confiança \\
\hline $\begin{array}{c}\text { Proeminên- } \\
\text { cia }\end{array}$ & 1 & & & & & & \\
\hline Desempenho &, $538(* *)$ & 1 & & & & & \\
\hline Imagem &, $573(* *)$ &, $784(* *)$ & 1 & & & & \\
\hline Julgamento &, $541(* *)$ &, $924(* *)$ &, $803(* *)$ & 1 & & & \\
\hline Sentimento &, $524(* *)$ & $863(* *)$ &, $780(* *)$ &, $899(* *)$ & 1 & & \\
\hline Ressonância & ,493(**) &, $812(* *)$ &, $730(* *)$ &, $860(* *)$ &, $849(* *)$ & 1 & \\
\hline Confiança &, $481(* *)$ &, $849(* *)$ &, $735(* *)$ &, $872(* *)$ &, $863(* *)$ &, $881(* *)$ & 1 \\
\hline
\end{tabular}


Em relação à Pirâmide de Ressonância de Marca é possível identificar a partir dos dados presentes na Tabela 2 que a ressonância possui uma maior correlação com os blocos sentimento e julgamento, conforme descreve a teoria, já que a ressonância é o estágio final da Pirâmide de Ressonância de Marca (KELLER, 2001). Todas as correlações foram estatisticamente significativas em $99 \%$. Além disso, a proeminência também possui fortes correlações com os outros blocos da pirâmide, também já descrito na teoria. A imagem tem uma forte correlação com o sentimento - conforme descrito na teoria referindo-se ao caminho emocional -, mas também tem uma forte correlação com o desempenho e com o julgamento que faz parte do caminho racional.

Além disso, em relação ao caminho racional, o desempenho apresenta a sua maior correlação com o julgamento conforme descrito na teoria. Inclusive esse valor é muito alto, acima de 0,92 .

No caso da confiança, ela vai apresentando maiores valores para as correlações enquanto percorre a Pirâmide de Ressonância de Marca. Ela possui a menor correlação com a proeminência, em seguida apresenta correlações também significativas com o desempenho e a imagem e essas correlações aumentam considerando-se os blocos julgamento e sentimento. Por fim, verifica-se que a confiança possui a sua maior correlação com o bloco final de ressonância de marca.

\section{CONSIDERAÇÕES FINAIS}

O objetivo do trabalho foi o de mensurar a ressonância de marca de uma IES. Os resultaods indicam que os itens da base da Pirâmide de Ressonância de Marca, tais como a proeminência e imagem da marca são melhor avaliados do que os itens que estão no topo da pirâmide, tal como ressonância de marca. Esses resultados estão de acordo com a teoria.

Como o estudo foi realizado com os alunos de uma IES, o alto valor obtido para a proeminência de marca ocorreu como esperado.

As implicações gerenciais em termos dos outros blocos da Pirâmide de Ressonância de Marca são inúmeras. O resultado do julgamento se torna mais importante ainda quando se considera a teoria da Pirâmide de Ressonância de Marca, a qual indica que a ressonância da marca depende fortemente do julgamento e dos sentimentos dos consumidores em relação à marca. Há de se considerar que o seu resultado foi melhor do que o resultado do desempenho e, de acordo com a teoria (KELLER, 2001), uma melhora na avaliação do desempenho da marca irá impactar positivamente o julgamento da marca e, consequentemente, irá melhorar ainda mais a ressonância (vínculo) entre a marca e os seus consumidores.

Por conseguinte, em relação à base da pirâmide, uma melhoria no processo de comunicação torna-se premente para impactar positivamente $\mathrm{o}$ desempenho $\mathrm{e}$ consequentemente o julgamento da marca. Ressalta-se que a IES obteve a melhor nota no resultado do Enade nos últimos quatro anos, sendo provavelmente a melhor IES particular no estado na qual está situada e mesmo assim, os itens que comparam a IES com as suas concorrentes possuem pior avaliação no conjunto de itens - questões - que formam os blocos de desempenho e julgamento.

O processo de melhoria da comunicação também gerará impactos na imagem e consequentemente nos sentimentos dos alunos em relação à IES. Além disso, o desempenho e a ressonância da marca apresentaram valores baixos em comparação com os outros blocos. 
Em relação à ressonância de marca, o resultado está de acordo com a teoria em virtude de que esse item depende da percepção e da avaliação dos outros cinco blocos da Pirâmide de Ressonância de Marca. No caso dessa pesquisa especificamente, o valor mais baixo em comparação com os outros blocos obtido indica que existe um caminho a ser percorrido pela IES para melhorar o vínculo dos seus alunos com a própria instituição. Além disso, o Modelo de Ressonância de Marca possui implicações gerenciais importante, pois, pode ser considerado um roteiro para os itens que devem ser melhorados com o intuito de se alcançar o relacionamento e fidelização da IES com os seus alunos, bem como para atingir um bom nível de comunicação boca a boca positivo por parte dos seus alunos. Nesse caso, os procedimentos e os modelos de qualidade de serviços podem ser úteis para os gestores melhorarem o desempenho dos serviços da IES com reflexos positivos para a ressonância de marca, a qual está mais fortemente correlacionada com os blocos de sentimentos e julgamento.

No caso mais específico da confiança, os resultados foram ruins. A partir da análise dos dados, pode-se sugerir que não adianta para a IES se esforçar para resolver os problemas em termos de ensino dos seus alunos, bem como se esforçar para satisfazer os seus alunos, caso eles não percebam esse tipo de atuação. Além disso, novamente é necessário verificar se os procedimentos de qualidade e prestação de serviços estão sendo executados de forma adequada e conjunta, verificar se esses procedimentos são coerentes com as expectativas dos alunos. A teoria já descrita no tópico de confiança do referencial teórico deixa claro que a resolução rápida dos problemas que os alunos enfrentam é um dos caminhos para melhorar a percepção de confiança na marca da IES. Além disso, na resolução de problemas dentro da IES, existe um "Centro de Atendimento ao Aluno" (CAA), no qual os funcionários deverão receber treinamento não somente na área técnica, mas também em termos comportamentais e de postura, notadamente no caso da empatia e presteza na prestação dos seus serviços. Esse pode ser um diferencial, o qual tem impacto tanto no bloco de julgamento, quanto no bloco de sentimentos na Pirâmide de Ressonância de Marca.

As contribuições teóricas desse estudo podem ser resumidas da seguinte forma: os valores das correlações obtidos em relação ao Modelo de Ressonância de Marca possuem validade nomológica e sugerem que o Modelo de Pirâmide de Ressonância de Marca existe para a IES estudada. Não foi realizada a verificação da cadeia nomológica, mas a validade nomológica - relação significativa entre as variáveis em termos teóricos - ocorreu. Em segundo lugar há de se considerar que não foram encontradas escalas de mensuração usadas em português e a sua tradução e aplicação de escalas para mensurar os blocos pode ser consideradas contribuições desse trabalho. Alem disso, a mensuração da confiança e a sua alta correlação com a ressonância de marca - conforme descrito por Chaudhuri e Holbrook (2001) - sugerem que os blocos da Pirâmide de Marca não somente podem ser usados para se alcançar a ressonância de marca, como também gerar uma marca com alta credibilidade para os seus consumidores.

Em termos das limitações desse estudo, a principal delas é referente à composição da amostra por conveniência, fato esse que limita a possibilidade de generalização dos resultados para todos os estudantes da IES, bem como pode causar viés em termos da avaliação da ressonância da marca da IES. Assim, um grupo de alunos que respondeu ao questionário pode ter uma avaliação pior em termos da confiança e de todos os outros blocos da Pirâmide de Ressonância de Marca, em virtude de problemas que possam ter ocorrido durante todo o curso. De outro lado, como estão estudando há anos na IES esses alunos podem avaliar com valores muito altos para a proeminência de marca. $O$ inverso pode ocorrer caso os respondentes sejam alunos que estão iniciando os seus estudos da IES, bem como fazem cursos de duração mais curta. 
Em relação às pesquisas futuras algumas sugestões que podem contribuir para um maior conhecimento sobre a mensuração da força da marca é testar modelos alternativos que possam se mostrar mais parcimoniosos e ao mesmo tempo com melhores características psicométricas das escalas atuais e também com um maior poder de explicação da variância explicada. Assim, a confiança poderia ser uma substituta para o desempenho e para a imagem? Ou talvez, somente para um desses blocos? Outra possibilidade seria que os blocos da Pirâmide de Ressonância da Marca não são úteis somente para a construção da ressonância da marca, mas também poderiam ser úteis para a construção de marcas confiáveis? No caso da força da marca, ela pode ser uma preditora acerca das intenções dos alunos em trocar de IES? A força da marca pode ser um indicador da entrada de novos alunos vindos de transferência de outras IES? Enfim, existem diversas possibilidades de novos estudos que contribuam em nível de contribuições teóricas e também em nível de implicações gerenciais.

\section{REFERÊNCIAS}

AAKER, D. Marcas: brand equity - gerenciando o valor da marca. 6. ed. São Paulo: Negócios Editora, 1998.

ADRIAN, S. An empirical study of the car modification market. 2014. 109f. Master Thesis. (Master in marketing). Umeå School of Business and Economics, Sweden, 2014.

AHRENS, A. R. v. Imaging Place: Interpreting Place Identity Through Consumer Marketing Techniques for Non-Profit, Community Development and Business Improvement Organizations. 2016. 61p. Masters Thesis (Master in Historic Preservation). University of Pennsylvania, Philadelphia, 2016.

AZIZ, N. A.; YASIN, N. M. Analyzing the brand equity and resonance of banking services: Malaysian consumer perspective. International Journal of Marketing Studies, v. 2, n. 2, p. 180-189, 2010.

BAIRD, M. D. Effects of Product Prototypicality on Brand Resonance in Brand Extensions. 2015. 390f. Thesis (Doctorade in Marketing). Curtin Business School, Bentley, 2015.

BALLESTER, E. D. Applicability of a brand trust scale across product categories: a multigroup invariance analysis. European Journal of Marketing, v. 38, n. 5/6; ABI/INFORM Global, 2004, p. 573-592.

BALLESTER, E. D.; ALEMÁN, J. L. M. Brand trust in the context of consumer loyalty. European Journal of Marketing, v. 35, n. 11/12; ABI/INFORM Global, 2001, p. 12381258.

BALLESTER, E. D; ALEMÁN, J. L. M. Development and validation of a brand trust scale. International Journal of Market Research, v. 45, n. 1, p. 35-54, 2003.

BASTOS, D. H.; MOURA, L. R. C.; CHRISTINO, J. M. M. Brand Equity da Usiminas: um estudo no setor siderúrgico brasileiro de aços planos. Gestão e Sociedade, v. 8, n. 20, p. 688$713,2014$.

BASTOS, D. H.; MOURA, L. R. C.; CHRISTINO, J. M. M. Mensuração, teste e validação da confiança na marca. Revista Capital Científico-Eletrônica (RCCee), v. 13, n. 2, p. 9-23, 2015. 
CHAUDHURI, A.; HOLBROOK, M. B. The chain of effects from brand trust and brand affect to brand performance: the role of brand loyalty. Journal of Marketing, v. 65, n. 2, p. 81-93, 2001.

CHOUDHURY, S.; KAKATI, R. P. An Analytical Study of Spillover Effect of Different Branding Elements on Customer-Based Brand Equity. IUP Journal of Brand Management, v. 11, n. 1, p. 30-46, 2014.

CRUZ, C. S. L. da. Um estudo sobre a satisfação e lealdade dos consumidores na Distribuição Moderna aplicando o Modelo Europeu de Satisfação do Cliente (ECSI): o Caso Português. Dissertação (Mestrado em Ciências Empresariais). Universidade Fernando Pessoa, Porto, 2013.

FARHANA, N.; ISLAM, S. Analyzing the brand equity and resonance of banking services: Bangladeshi consumer perspective. World Review of Business Research, v. 2, n. 4, p. 148163, 2012.

FORNELL, C. et al. The American customer satisfaction index: nature, purpose, and findings. the Journal of Marketing, v. 60, n. 4, p. 7-18, 1996.

GAUTAM, V.; KUMAR, M.. An Empirical Investigation to Analyze the Brand Equity and Resonance of Banking Services: Evidence from India. Management, v. 7, n. 1, p. 3-16, 2012.

GRONROOS, C. Marketing: gerenciamento e serviços. 2.ed. Rio de Janeiro: Elsevier, 2003.

GURVIEZ, P.; KORCHIA, M., Proposition d'une échelle de mesure multidimensionnelle de la confiance dans la marque. Recherche et Applications en Marketing, v. 17, n. 3, p. 41-61. 2002.

HAIR, J. F. et al., Análise multivariada de dados. 6. ed. Porto Alegre: Bookman, 2009.

JARVENPAA, S. L.; STAPLES, D. S. The use of collaborative electronic media for information sharing: an exploratory study of determinants. The Journal of Strategic Information Systems, v. 9, n. 2, p. 129-154, 2000.

KAU, A.; LOH, E. The effects of service recovery on consumer satisfaction: a comparison between complaints and non-complaints. Journal of Services Marketing. v. 20, n.2, p. 101$111,2006$.

KAVEH, M.; MOSAVI, S. A.; GHAEDI, M. The application of european customer satisfaction index (ECSI) model in determining the antecedents of satisfaction, trust and repurchase intention in five-star hotels in Shiraz, Iran. African Journal of Business Management, v. 6, n. 1, p. 6103-6113, 2012.

KELLER, K. L. Conceptualizing, measuring, and managing customer-based brand equity. Journal of Marketing, v. 57, n. 1, p. 1-22, 1993.

KELLER, K. L. Building customer-based brand equity. Marketing Management, v. 10, n. 2, p. 14-19, 2001

KELLER, K. L. Reflections on customer-based brand equity: perspectives, progress, and priorities. AMS Review, p. 1-16, 2016. 
KOETZ, C. I. et al. O papel da confiança na marca na intenção de adoção de novas tecnologias em trocas Business-to-Consumer. In: ENANPAD - ENCONTRO NACIONAL DOS PROGRAMAS DE PÓS-GRADUAÇÃO EM ADMINISTRAÇÃO, XXXIII, 2009. Rio de Janeiro. Anais eletrônicos... São Paulo: Anpad, 2009.

KOTLER, P.; KELLER, K. L. Administração de Marketing. 14. ed. São Paulo: Pearson Education, 2012.

LOURO, M. J. S. Modelos de avaliação de marca. Revista de Administração de empresas, v. 40, n. 2, p. 26-37, 2000.

MALHOTRA, N. K. Pesquisa de Marketing: uma orientação aplicada. 6. ed. Porto Alegre: Bookman, 2011.

MÁRKUS, A.; FALLMYR, J. Framing the Brand. 2014. 110f. Master`s Thesis (Doctorade in Strategy, Organization, Leadership). Copenhagen Business School, Copenhagen, 2014.

NUNNALY, Jum C.; BERNSTEIN, Ira H. Psychometric Theory. 3. ed. New York: McGraw-Hill, 1994.

RAUT, U. R.; BRITO, P. Q. An Analysis of brand relationship with the perceptive of customer based brand equity pyramid. Working Papers (FEP) - University of Porto, (526), p. $1-17,2014$.

RAUT, U. R. Analysis of brand resonance amongst young consumers with reference to select product categories. 2015. 235f. Tese (doutorado em administração e gestão de negócios). Universidade do Porto, Portugal, 2015.

ROSENBERGER III, P. J. Brand trust: an Australian replication of a two-factor structure. In: ANZMAC - AUSTRALIAN AND NEW ZEALAND MARKETING ACADEMY, 2009. Proceedings... Melbourne: ANZMAC, 2009.

SANDHE, A. A. An exploratory study of brand equity of a commercial bank in Vadodara, India. Independent Journal of Management \& Production, v. 7, n. 2, p. 289-302, 2016.

TAVARES, M. C. Gestão de marcas: construindo marcas de valor. 1. ed. São Paulo: Harbra, 2008.

TERRES, M. da S. et al. O papel da confiança na marca na intenção de adoção de novas tecnologias. RAI: revista de administração e inovação, v. 7, n. 4, p. 162-185, 2011.

TRI, H. M. Branding Implementation of SMEs in Vietnam. Case: Alpine Creative Ltd. 2014. 67f. Tese (Doctorade in International Business). Saimaa University of Applied Sciences. Lappeenranta, Finland, 2014.

TSUI-HSU TSAI, T.; JING LIN, A.; Y. LI, E. The effect of philanthropic marketing on brand resonance and consumer satisfaction of CSR performance: does media self-regulation matter?.

Chinese Management Studies, v. 8, n. 3, p. 527-547, 2014.

VERMA, P. Analysis of Brand Equity and Resonance of Private Banking Services in India. Pacific Business Review International, v. 5, n. 9, p. 59-66, 2012.

YOO, B.; DONHTHU, N. Developing and validating a multidimensional consumer-based brand equity scale. Journal of Business Research, v.52, n.1, 1-14, 2001. 